\title{
DOES ACCOUNTING CONSERVATISM AFFECT SHAREHOLDER VALUE IN THE U.S. AIRLINE INDUSTRY?
}

\author{
Bert J. Zarb, Embry-Riddle Aeronautical University, Daytona Beach, Florida, U.S.A.
}

dx.doi.org/10.18374/JIFE-20-3.6

\begin{abstract}
Conservatism is one of the most important concepts in financial accounting. Over the years, several studies have operationalized the qualitative nature of this concept. Watts (2003) refers to conservatism as "the differential verifiability required for recognition of profits versus losses." In his seminal work, Basu (1997) studied the timeliness of earnings recognition with respect to stock returns and found that earnings reflect "bad news" faster than "good news."Prior studies of accounting conservatism have focused on the banking industry (Alali \& Jaggi, 2011), high-tech versus low-tech firms (Kwon, Yin, and Han, 2006), emerging markets (Elbannan, 2011), and a large number of international markets (Anadarajan, Francis, Hasan, and John, 2011) while Kothari, Ramanna, and Skinner (2010), demonstrated the benefits of accounting conservatism in the debt market. Against this background, this study proposes to investigate whether accounting conservatism affects shareholder value in the U.S. airline industry.
\end{abstract}

Keywords: Accounting conservatism, shareholder value, and airline industry. 